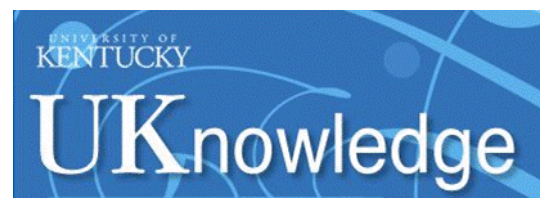

University of Kentucky

UKnowledge

Nursing Faculty Publications

College of Nursing

9-2017

\title{
Other Tobacco Product Use Among Sexual Minority Young Adult Bar Patrons
}

Amanda Fallin-Bennett

University of Kentucky, amanda.fallin@uky.edu

Nadra E. Lisha

University of California - San Francisco

Pamela M. Ling

University of California - San Francisco

Follow this and additional works at: https://uknowledge.uky.edu/nursing_facpub

Part of the Lesbian, Gay, Bisexual, and Transgender Studies Commons, Nursing Commons, Preventive Medicine Commons, and the Substance Abuse and Addiction Commons

Right click to open a feedback form in a new tab to let us know how this document benefits you.

\section{Repository Citation}

Fallin-Bennett, Amanda; Lisha, Nadra E.; and Ling, Pamela M., "Other Tobacco Product Use Among Sexual Minority Young Adult Bar Patrons" (2017). Nursing Faculty Publications. 41.

https://uknowledge.uky.edu/nursing_facpub/41

This Article is brought to you for free and open access by the College of Nursing at UKnowledge. It has been accepted for inclusion in Nursing Faculty Publications by an authorized administrator of UKnowledge. For more information, please contact UKnowledge@lsv.uky.edu. 


\section{Other Tobacco Product Use Among Sexual Minority Young Adult Bar Patrons}

Digital Object Identifier (DOI)

https://doi.org/10.1016/j.amepre.2017.03.006

\section{Notes/Citation Information}

Published in American Journal of Preventive Medicine, v. 53, issue 3, p. 327-334.

() 2017 Published by Elsevier Inc. on behalf of American Journal of Preventive Medicine

This manuscript version is made available under the CC-BY-NC-ND 4.0 license

https://creativecommons.org/licenses/by-nc-nd/4.0/.

The document available for download is the author's post-peer-review final draft of the article. 
Am J Prev Med. 2017 September ; 53(3): 327-334. doi:10.1016/j.amepre.2017.03.006.

\title{
Other Tobacco Product Use Among Sexual Minority Young Adult Bar Patrons
}

\author{
Amanda Fallin-Bennett, PhD, RN ${ }^{1}$, Nadra E. Lisha, PhD $^{2}$, and Pamela M. Ling, MD, MPH ${ }^{2}$ \\ ${ }^{1}$ Tobacco Policy Research Program, University of Kentucky College of Nursing, Lexington, \\ Kentucky \\ 2Division of General Internal Medicine, and Center for Tobacco Control Research and Education, \\ University of California San Francisco, San Francisco California
}

\begin{abstract}
Introduction-Lesbian, gay, and bisexual (LGB) individuals smoke at rates 1.5-2 times higher than the general population, but less is known about LGB consumption of other tobacco products (OTPs) and gender differences. OTP use among young adult LGB bar patrons and the relationship among past quit attempts, intention to quit, and binge drinking with OTP use was examined.
\end{abstract}

Methods-A cross-sectional survey of young adults (aged 18-26) in bars/nightclubs in seven U.S. cities between 2012 and 2014 (N=8,010; 1,101 LGB participants) was analyzed in 2016. Logistic regressions examined current use of five OTPs (cigarillos, electronic cigarettes, hookah, chewing tobacco, and snus) and sexual minority status, adjusting for demographics and comparing LB women and GB men with their heterosexual counterparts.

Results-LGB bar/nightclub patrons used all OTPs more than their heterosexual counterparts. LB women were more likely than heterosexual women to use cigarillos, electronic cigarettes, hookah, chew, and snus. GB men were more likely than heterosexual men to smoke cigarillos, electronic cigarettes, hookah, and use chew and snus. Past-year quit attempt was associated with increased odds of electronic cigarette use in men and women, and increased odds of dual use (cigarettes and OTPs) among men. Intention to quit was negatively associated with dual use among women. Binge drinking was associated with increased use of all OTPs across genders.

Conclusions-LGB bar-going young adults are at higher risk for OTP use than their heterosexual counterparts. Bar-based interventions are needed to address all forms of tobacco use in this high-risk group.

\section{INTRODUCTION}

Tobacco use, the leading cause of preventable death and disease, ${ }^{1}$ is an issue of social justice and health equity. ${ }^{2}$ Despite overall declines, smoking rates remain high among lesbian, gay, and bisexual (LGB) individuals. A recent nationally representative survey found $32.8 \%$ of

Address correspondence to: Pamela M. Ling, MD, MPH, 530 Parnassus Avenue, Suite 366, University of California San Francisco, San Francisco CA 94143-1390. pamela.ling@ucsf.edu.

No financial disclosures were reported by the authors of this paper. 
LGB and transgender (LGBT) individuals were smokers, compared with $19.5 \%$ of their heterosexual, cisgender counterparts. ${ }^{3}$

Although it is well established that sexual minorities (defined as individuals whose sexual orientation, identity, or behaviors differ from heterosexual) smoke more than the general population, less is known about use of other tobacco products ([OTPs], i.e., cigarillos, hookah, electronic cigarettes [e-cigarettes], chew, and snus) or dual use (cigarettes and OTPs). All tobacco products increase risk for nicotine addiction. ${ }^{1}$ Smokeless tobacco causes oral, esophageal, and pancreatic cancers, and may increase heart disease and stroke. ${ }^{4}$ Young adults who use OTPs are more likely to smoke than those who do not use OTPs. ${ }^{5}$ In addition, dual use may complicate smoking-cessation attempts. ${ }^{6,7}$

National studies indicate that current use of e-cigarettes, ${ }^{8,9}$ hookah, ${ }^{3,9}$ and cigar/cigarillos ${ }^{3}$ is higher among LGB individuals than their heterosexual counterparts. However, among LGB adults, there may be important gender differences in tobacco use. Sexual minority women smoke cigars or cigarillos more than heterosexual women, but sexual minority men smoke cigars or cigarillos less than heterosexual men. ${ }^{8}$ This study examines OTPs and dual use (currently smoking cigarettes and using OTPs) among young adult LGB bar/nightclub patrons.

In addition, a deeper understanding is needed about why LGB young adults might use OTPs. On one hand, OTPs have been promoted as harm reduction or smoking-cessation aids. According to a review of e-cigarette retail websites, the majority contained a health (95\%) or smoking-cessation (64\%) claim. ${ }^{10}$ Smokeless tobacco has also been associated with past smoking quit attempts. ${ }^{6}$ One national survey found that smokers using both cigarettes and smokeless tobacco were more likely to have made a quit attempt. ${ }^{11}$

On the other hand, LGB youth and young adults are more likely to use tobacco, alcohol, and illicit drugs. ${ }^{12-14}$ There is a well-documented link between alcohol and tobacco use. ${ }^{15-18}$ For example, young adult non-daily smokers are more likely to smoke on days when they are drinking alcohol. ${ }^{15}$ Alcohol leads to a dose-dependent increase in cigarette cravings among social smokers, ${ }^{17}$ and alcohol use is a strong predictor of OTP use among women ${ }^{19}$ and LGB young adults. ${ }^{20}$ Therefore, it is possible that OTP use reflects polysubstance use, rather than harm reduction behavior.

The goals of this study were to (1) compare OTP use and dual use (use of cigarettes and another tobacco product) among young adult bar patrons based on sexual orientation and gender and (2) explore potential correlates of OTP use and dual use that might reflect risk taking or risk reduction behavior.

\section{METHODS}

\section{Study Sample}

This study was approved by the University of California San Francisco IRB. A crosssectional sample of young adults $(\mathrm{N}=8,010)$ was recruited between 2012 and 2014 from bars/ nightclubs in seven U.S. cities (Tucson, Los Angeles, San Diego, Albuquerque, San 
Francisco, Oklahoma City, and Nashville). Data analysis took place in 2016. All participants provided informed consent. Participants were recruited using time location sampling, ${ }^{21}$ a technique that has been used with "hard to reach" populations, and the methods used here have been described previously. ${ }^{22,23}$ Similar to past tobacco marketing strategies in bars, the research team worked with a marketing consultant with expertise in young adult bar/ nightclub events to identify party promoters, bartenders, DJs, and other entertainers in the scene. Interviews were conducted with these opinion leaders in each city to generate a census of the most popular young adult bars/nightclubs. Focus groups with young adult bar patrons also generated additional names and validated the popularity of the bars and clubs on the list. The process was repeated until saturation was reached. Then, venues and times were randomly selected, and trained data collectors invited all eligible participants (i.e., aged 1826 years, not visibly intoxicated) to fill out a paper survey. Participants received a $\$ 5$ incentive on the spot. All data collection staff were familiar and comfortable working in a bar/nightclub environment. They received a standard training on survey protocol methods, human subjects research, and supervised field trials for data collection. In addition, data protocol adherence was monitored for quality using "secret shoppers" unknown to study personnel.

A three-form planned missing data design was used with three survey instruments, each containing a core set of items (demographics and current tobacco use), and two variant sets of questions that were on two of the three instruments. ${ }^{24}$ This planned missing design was used to decrease participant burden while maximizing number and variety of questions; participants completed one of the three randomly selected questionnaires. The items in this manuscript that were only present on two of the three forms were use of hookah, snus, cigarillos, and e-cigarettes. Imputation of data missing by design is described below.

\section{Measures}

Sexual orientation was assessed with the question: What is your sexual orientation? with responses: straight, gay, bisexual, or other.

Participants reported the number of days in the past 30 days that they did each of the following: smoked at least one cigarette; used spit tobacco, chew, or dip; smoked tobacco using a hookah; used "snus" tobacco; smoked a "black and mild" or other brand cigarillo; or smoked an e-cigarette or electronic cigarette. Responses were dichotomized, counting a response of one or more in the past 30 days as "current use," and 0 days as not currently using. Dual use was defined as current cigarette smoking and current use of at least one OTP.

Sex was self-reported (male/female). Race/ethnicity was determined by two questions: Are you of Hispanic/Latino, or Spanish origin? (yes/no) and What is your race? (African American/Asian/White/Hawaiian or Pacific Islander/American Indian or Alaskan Native/ more than one race). Responses were combined into four categories: "non-Hispanic white," "Hispanic," "non-Hispanic black," and "non-Hispanic other." Participants reported their "current education status" (I go to college in the local area/I go to a college NOT in the local area/I have graduated from college/I dropped out of college or I graduated high school/ $G E D)$. Responses were combined into three categories: "in college," "college graduate," or "no college/dropped out/high school/GED." 
Quit attempts were measured by asking: During the past 12 months, have you stopped smoking tobacco for 1 day or longer because you were trying to quit? ${ }^{25}$ with three response categories (I have not tried to quit/I have tried to quit/I have not smoked in the last 12 months). Those who had not smoked were recoded as missing for this analysis. Intention to quit was assessed asking: What best describes your intentions regarding quitting cigarette smoking?25 Those who responded will quit in the next 6 months, will quit in the next month, I am currently trying to quit, or I have already quit smoking completely were coded dichotomously as "intending to quit," and those who responded are not planning to quit or may quit in the future, but not in the next 6 months were coded as "no intention to quit." Participants also reported how many days in the past 30 that they drank five drinks or more within a few hours. This was dichotomized into yes ( $\geq 1$ days) or no ( 0 days).

\section{Statistical Analysis}

All data analysis took place in 2016. The mean age and SD, frequency of the different categories of education and race/ethnicity, and prevalence of current (past-30 day) use of all tobacco products were calculated, stratified by gender. Within each gender, LGB participants were compared with non-LGB participants using $t$-tests for continuous variables and chisquare tests for categorical variables. Given the three-form planned missing design, it was assumed the data were missing completely at random ${ }^{24}$ and thus the inferential analyses were conducted by using multiple imputations. Logistic regressions examined use versus non-use of five OTPs (cigarillos, e-cigarettes, hookah, chewing tobacco, and snus) based on sexual minority status, adjusting for age, education, and race/ethnicity. Separate models were created by gender, comparing LB women and GB men with their heterosexual counterparts. For each regression model, ten imputations were performed using the threestep approach (imputation, analysis, and pooling) in SAS (version 9.3, 2011). The data augmentation algorithm and Markov Chain Monte Carlo method, which assumes that all the variables in the imputation model have a joint multivariate distribution, were used. Missing data are filled in by drawing from a conditional distribution of the missing data, given the observed data. Simulation studies have shown that this method is highly reliable even when normality assumptions are not met. ${ }^{26,27}$

In three additional sets of analyses, the logistic regressions were conducted using identical models stratified by gender with each of the OTP as outcomes, adding three additional predictor variables: (1) past-year quitting; (2) quitting intentions; and (3) past-30 day binge drinking.

\section{RESULTS}

Of the 8,010 participants, 1,101 (14\%) self-identified as LGB. The mean age was 24 years, which is expected in samples from a generally 21 -and-over environment. The total sample was about equally male and female and racially/ethnically diverse, with variation in education (Table 1). The LGB participants were more likely to be female, had less education, and were less likely to be non-Hispanic white compared with the non-LGB participants. Among men, $6.2 \%$ of the sample self-identified as gay, $3.0 \%$ were bisexual, and 
$2.7 \%$ identified as "other"; among women, $3.9 \%$ of the sample self-identified as lesbian, $8.1 \%$ bisexual, and $2.7 \%$ identified as "other."

Overall, there were high rates of tobacco use, and compared with heterosexual/straight participants, more LGB participants reported current use of every tobacco product (Tables 1 and 2). More than 50\% of LGB bar patrons reported current tobacco use, with more than half smoking cigarettes, nearly one in three using hookah, and one in four using e-cigarettes. More LGB participants reported smoking (54.6\% vs $41 \%, p<0.0001$ ), use of both combustible tobacco products (cigarillos: $16.6 \%$ vs $9.5 \%, p<0.0001$; hookah: $27.6 \%$ vs $20.2 \%, p<0.0001$ ), and non-combustible products (e-cigarettes: $24.2 \%$ vs $16.8 \%, p<0.0001$; chew: $10.3 \%$ vs $7.2 \%, p<0.0001$; snus: $9.7 \%$ vs $4.7 \%, p<0.0001)$. In addition, a higher percentage of LGB individuals reported dual use compared with heterosexual individuals $(30.2 \%$ vs $18.6 \%, p<0.0001)$.

After adjusting for age, race/ethnicity, education, and site of data collection, sexual orientation was an independent predictor for use of all OTPs and dual tobacco products among both women and men (Tables 3 and 4). Among female LB participants, the increased odds of OTP use ranged from a $61 \%$ increased odds of using hookah (AOR=1.61, 95\% $\mathrm{CI}=1.16,2.23)$ to a 2.6 higher odds of snus use ( $\mathrm{AOR}=2.60,95 \% \mathrm{CI}=1.32,5.14)$. Among male GB participants, increased adjusted odds ranged from 1.43 (95\% CI=1.08, 1.90) for hookah to $2.37(95 \% \mathrm{CI}=1.62,3.45)$ for snus. Both female and male sexual minority participants had increased odds of dual use (female sexual minority dual use: AOR=2.27, $95 \% \mathrm{CI}=1.67,3.12$; male sexual minority dual use: $\mathrm{AOR}=1.72,95 \% \mathrm{CI}=1.38,2.13)$. In both models, sexual orientation was the only significant predictor of dual use, other than college education. College graduates had a lower odds of dual use compared with participants not attending college.

Among female participants, independent of sexual minority status, African Americans had nearly three times the odds of using cigarillos $(\mathrm{AOR}=3.3,95 \% \mathrm{CI}=1.6,7.0)$ and increased odds for the use of hookah $(\mathrm{AOR}=1.9,95 \% \mathrm{CI}=1.7,3.0)$ and chew $(\mathrm{AOR}=2.1,95 \% \mathrm{CI}=1.03$, 4.2). Hispanic participants also had increased odds for use of hookah ( $\mathrm{AOR}=1.6,95 \%$ $\mathrm{CI}=1.2,2.1)$ and snus ( $\mathrm{AOR}=2.2,95 \% \mathrm{CI}=1.1,4.3)$. Among men, African Americans had increased odds of using cigarillos ( $\mathrm{AOR}=2.2,95 \% \mathrm{CI}=1.3,3.9)$ and lower odds of using chewing tobacco $(\mathrm{AOR}=0.6,95 \% \mathrm{CI}=0.3,0.9)$ and cigarettes $(\mathrm{AOR}=0.7,95 \% \mathrm{CI}=0.5,0.9)$. Hispanic/Latino men had reduced odds of using chewing tobacco (AOR=0.7, 95\% CI= $0.5-$ $0.9)$ and cigarettes $(\mathrm{AOR}=0.8,95 \% \mathrm{CI}=0.7,0.9)$, but increased odds of using snus ( $\mathrm{AOR}=1.5,95 \% \mathrm{CI}=1.01,2.2)$.

Having made a quit attempt in the past year was associated with increased odds of ecigarette use in both men $(\mathrm{AOR}=1.6,95 \% \mathrm{CI}=1.3,2.1)$ and women $(\mathrm{AOR}=1.5,95 \% \mathrm{CI}=1.1$, $2.0)$ and increased odds of dual use in men $(\mathrm{AOR}=1.3,95 \% \mathrm{CI}=1.1,1.6)$ (data not shown in tables). Quitting was not associated with use of any of the other OTPs. LGB participants were more likely to use all products even when controlling for quit attempts, except for men in the regression for hookah use. 
Intentions to quit were associated with decreased odds of cigarette smoking in men $(\mathrm{AOR}=0.4,95 \% \mathrm{CI}=0.3,0.5)$ and women $(\mathrm{AOR}=0.4,95 \% \mathrm{CI}=0.3,0.5)$ and dual use in women $(\mathrm{AOR}=0.7,95 \% \mathrm{CI}=0.6,0.9)$. Intention to quit was not associated with use of any OTP. LGB respondents remained significantly more likely to use all OTPs, controlling for intentions to quit.

Binge drinking was associated with increased odds of use of all OTPs. For women, binge drinking was associated with increased odds of use for cigarillos ( $\mathrm{AOR}=2.0,95 \% \mathrm{CI}=1.5$, 3.5); e-cigarettes ( $\mathrm{AOR}=2.3,95 \% \mathrm{CI}=1.5,3.5)$; hookah ( $\mathrm{AOR}=2.0,95 \% \mathrm{CI}=1.5,2.7)$; chew ( $\mathrm{AOR}=4.6,95 \% \mathrm{CI}=2.0,10.8)$; cigarettes $(\mathrm{AOR}=3.0,95 \% \mathrm{CI}=2.4,3.7)$; and dual use $(\mathrm{AOR}=2.9,95 \% \mathrm{CI}=2.2,3.8)$. For men, binge drinking was associated with increased odds of use for cigarillos $(\mathrm{AOR}=2.0,95 \% \mathrm{CI}=1.5,3.5)$; e-cigarettes $(\mathrm{AOR}=2.1,95 \% \mathrm{CI}=1.6,2.8)$; hookah ( $\mathrm{AOR}=2.2,95 \% \mathrm{CI}=1.8,2.9)$; chew $(\mathrm{AOR}=3.7,95 \% \mathrm{CI}=2.6,5.4)$; snus ( $\mathrm{AOR}=1.8$, $95 \% \mathrm{CI}=1.2,2.6)$; cigarettes $(\mathrm{AOR}=3.9,95 \% \mathrm{CI}=3.1,4.8)$; and dual use $(\mathrm{AOR}=4.6,95 \%$ $\mathrm{CI}=3.3,6.3)$.

\section{DISCUSSION}

Young adult LGB bar patrons used OTPs and also combined cigarettes with OTPs more than their heterosexual counterparts. This complements a large body of literature indicating that LGB individuals smoke cigarettes at higher rates ${ }^{28-30}$ and a recent study reporting perceptions that smoking is part of LGBT culture. ${ }^{31}$ This study suggests these normative views may extend to many non-cigarette tobacco products.

These findings also support previous findings that LGB OTP use is strongly linked to binge drinking. ${ }^{20}$ This complements a large body of literature indicating increased risk for multiple types of substance use (e.g., tobacco, alcohol, and illicit drugs) among LGB individuals. ${ }^{7,12-14,28,32,33}$ The high rates of smoking, OTP use, and binge drinking in this study sample demonstrate the need for bar-based interventions targeting substance use among high-risk LGB young adults.

Community-based interventions also have the potential to change pro-tobacco bar environments. The LGBT community may be particularly well suited to leverage past experience with community organizing and advocacy for equal rights to take action against predatory tobacco marketing practices. ${ }^{34}$ For example, the Just for Us LGBT Tobacco Prevention Project documented tobacco company tobacco promotions in bars in San Jose, California, including distribution of free e-cigarettes. The group's "Butt Out of Our Bars" campaign brought together public health and LGBT community organizations to raise awareness about this issue. Ultimately, a city ordinance was passed prohibiting the distribution of free/low-cost tobacco products in bars. ${ }^{35}$ Partnerships between the public health and LGBT community may support lasting changes in pro-tobacco bar environments.

The U.S. Food and Drug Administration's public education campaign, This Free Life, promotes tobacco-free lifestyles using messages from LGBT young adults. This study suggests OTPs and dual use of OTPs and cigarettes should be addressed by public education campaigns and community partnerships. 
The strong association between OTP use and binge drinking but not intention to quit smoking suggests OTP use in general is more likely a part of multiple linked risk behaviors, than an attempt to quit smoking cigarettes. However, past-year quit attempts were associated with increased odds specifically for e-cigarettes, and dual use (use of cigarettes plus any OTP) for men. This suggests that e-cigarette use might differ from other OTPs and might be part of an attempt to quit smoking. This finding is consistent with multiple studies finding ecigarette use among smokers is associated with intention to quit or quit attempts. ${ }^{36,37}$ However, a meta-analysis of studies found that e-cigarette users were less likely to successfully quit smoking, ${ }^{6}$ and a recent Cochrane review found no evidence e-cigarettes were more effective for cessation than Food and Drug Administration-approved therapy. ${ }^{38}$

In addition to community campaigns, individual cessation efforts should be targeted to the LGBT population. Smoking-cessation programs tailored for LGBT patients ${ }^{39,40}$ should include OTPs. Clinicians should explore readiness to quit using cigarettes, with patients using e-cigarettes or using both cigarettes and OTPs. It is important for clinicians to support their patients in their smoking-cessation attempts, but also to inform them that the Food and Drug Administration has not approved OTP use for smoking cessation. ${ }^{41}$

\section{Limitations}

This study has several limitations. The sample did not have sufficient numbers of LGB participants to make comparisons between genders and each sexual orientation (e.g., between lesbian and bisexual women), and previous research ${ }^{28}$ has indicated that bisexual individuals have higher-risk tobacco use profiles. Although the population was accessed via randomized sampling, findings cannot be extended beyond the high-risk population of bar patrons. In addition, participants were recruited from select cities across the U.S. and the cities were not selected based on representativeness of the LGB community. The study did not include a measure of population-level (e.g., stress, depression) or LGBT-specific (e.g., internalized homophobia) factors that can influence smoking. Gender identity beyond "male" or "female" was not captured, and so data do not reflect those who identify outside the gender binary. Future research is also needed with a larger representation of LGB racial/ ethnic minorities. All sexual orientation and tobacco use measures were based on self-report, and thus subject to reporting bias. However, this study focused on a population that is both hard to reach and has substantial rates of tobacco use, and compared sexual minority and heterosexual participants based on gender.

\section{CONCLUSIONS}

Young adult LGB bar/nightclub patrons use OTPs more than their heterosexual counterparts. This study complements the research demonstrating high rates of substance use among LGBT bar patrons, and indicates the need for bar-based interventions. Further research to understand LGB individuals' motivations behind OTP and dual product use may guide tailored tobacco treatment for this high-risk population. 


\section{Acknowledgments}

This research was supported by the National Cancer Institute at NIH (Grant Number U01-CA154240). This project was also supported by Grant Number K12 DA035150 from the Office of Women's Health Research and the National Institute on Drug Abuse at NIH and the Oklahoma Tobacco Settlement Endowment Trust. The content is solely the responsibility of the authors and does not necessarily represent the official views of NIH.

\section{References}

1. U.S. DHHS. The Health Consequences of Smoking-50 Years of Progress: A Report of the Surgeon General. Atlanta, GA: CDC, National Center for Chronic Disease Prevention and Health Promotion, Office on Smoking and Health; 2014.

2. Healton C, Nelson K. Reversal of misfortune: viewing tobacco as a social justice issue. Am J Public Health. 2004; 94(2):186-191. https://doi.org/10.2105/AJPH.94.2.186. [PubMed: 14759926]

3. King BA, Dube SR, Tynan MA. Current tobacco use among adults in the United States: findings from the National Adult Tobacco Survey. Am J Public Health. 2012; 102(11):e93-e100. https:// doi.org/10.2105/AJPH.2012.301002. [PubMed: 22994278]

4. WHO. IARC Monographs on the Evaluatoin of Carcinogenic Risks to Humans. Volume 89: Smokeless Tobacco and Some Tobacco Specific N-Nitrosamines. Lyon, France: WHO, International Agency for Research on Cancer; 2007.

5. Delnevo CD, Villanti AC, Wackowski OA, Gundersen DA, Giovenco DP. The influence of menthol, e-cigarettes and other tobacco products on young adults' self-reported changes in past year smoking. Tob Control. 2016; 25(5):571-574. https://doi.org/10.1136/tobaccocontrol-2015-052325. [PubMed: 26243809]

6. Kalkhoran S, Glantz SA. E-cigarettes and smoking cessation in real-world and clinical settings: a systematic review and meta-analysis. Lancet Respir Med. 2016; 4(2):116-128. https://doi.org/ 10.1016/S2213-2600(15)00521-4. [PubMed: 26776875]

7. Popova L, Ling PM. Alternative tobacco product use and smoking cessation: a national study. Am J Public Health. 2013; 103(5):923-930. https://doi.org/10.2105/AJPH.2012.301070. [PubMed: 23488521]

8. Emory K, Kim Y, Buchting F, Vera L, Huang J, Emery SL. Intragroup variance in lesbian, gay, and bisexual tobacco use behaviors: evidence that subgroups matter, notably bisexual women. Nicotine Tob Res. 2016; 18(6):1494-1501. https://doi.org/10.1093/ntr/ntv208. [PubMed: 26377512]

9. Johnson SE, Holder-Hayes E, Tessman GK, King BA, Alexander T, Zhao X. Tobacco product use among sexual minority adults: findings from the 2012-2013 National Adult Tobacco Survey. Am J Prev Med. 2016; 50(4):e91-e100. https://doi.org/10.1016/j.amepre.2015.07.041. [PubMed: 26526162]

10. Grana RA, Ling PM. "Smoking revolution": a content analysis of electronic cigarette retail websites. Am J Prev Med. 2014; 46(4):395-403. https://doi.org/10.1016/j.amepre.2013.12.010. [PubMed: 24650842]

11. Messer K, Vijayaraghavan M, White MM, et al. Cigarette smoking cessation attempts among current U.S. smokers who also use smokeless tobacco. Addict Behav. 2015; 51:113-119. https:// doi.org/10.1016/j.addbeh.2015.06.045. [PubMed: 26253939]

12. Kelly J, Davis C, Schlesinger C. Substance use by same sex attracted young people: prevalence, perceptions and homophobia. Drug Alcohol Rev. 2015; 34(4):358-365. https://doi.org/10.1111/ dar.12158. [PubMed: 24890312]

13. Rosario M, Reisner SL, Corliss HL, Wypij D, Calzo J, Austin SB. Sexual-orientation disparities in substance use in emerging adults: a function of stress and attachment paradigms. Psychol Addict Behav. 2014; 28(3):790-804. https://doi.org/10.1037/a0035499. [PubMed: 25134050]

14. Marshal MP, Friedman MS, Stall R, Thompson AL. Individual trajectories of substance use in lesbian, gay and bisexual youth and heterosexual youth. Addiction. 2009; 104(6):974-981. https:// doi.org/10.1111/j.1360-0443.2009.02531.x. [PubMed: 19344440]

15. Harrison EL, McKee SA. Young adult non-daily smokers: patterns of alcohol and cigarette use. Addict Behav. 2008; 33(5):668-674. https://doi.org/10.1016/j.addbeh.2007.11.012. [PubMed: 18093745] 
16. Rose JE, Brauer LH, Behm FM, Cramblett M, Calkins K, Lawhon D. Psychopharmacological interactions between nicotine and ethanol. Nicotine Tob Res. 2004; 6(1):133-144. https://doi.org/ 10.1080/14622200310001656957. [PubMed: 14982697]

17. King AC, Epstein AM. Alcohol dose-dependent increases in smoking urge in light smokers. Alcoholism Clin Exp Res. 2005; 29(4):547-552. https://doi.org/10.1097/01.ALC. 0000158839.65251.FE.

18. Falk D, Yi H, Hiller-Sturmhofel S. An epidemiologic analysis of co-occuring alcohol and tobacco use disorders: findings from the National Epidemiologic Survey on alcohol and related conditions. Alcohol Res Health. 2006; 29(3):162-171. [PubMed: 17373404]

19. Kvaavik E, Lund I, Nygard M, Hansen BT. Lifestyle correlates of female snus use and smoking: a large population-based survey of women in Norway. Nicotine Tob Res. 2016; 18(4):431-436. https://doi.org/10.1093/ntr/ntv126. [PubMed: 26069033]

20. Rath JM, Villanti AC, Rubenstein RA, Vallone DM. Tobacco use by sexual identity among young adults in the United States. Nicotine Tob Res. 2013; 15(11):1822-1831. https://doi.org/ 10.1093/ntr/ntt062. [PubMed: 23680918]

21. Raymond, HF., Ick, T., Grasso, M., Vaudrey, J., McFarland, W. Resource Guide: Time Location Sampling. 2. San Francisco Department of Public Health, HIV Epidemiology Section, Behavioral Surveillance Unit; 2010.

22. Jiang N, Ling PM. Impact of alcohol use and bar attendance on smoking and quit attempts among young adult bar patrons. Am J Public Health. 2013; 103(5):e53-e61. https://doi.org/10.2105/ AJPH.2012.301014. [PubMed: 23488485]

23. Fallin A, Neilands TB, Jordan JW, Ling PM. Social branding to decrease lesbian, gay, bisexual, and transgender young adult smoking. Nicotine Tob Res. 2015; 17(8):983-989. https://doi.org/ 10.1093/ntr/ntu265. [PubMed: 26180223]

24. Graham JW, Taylor BJ, Olchowski AE, Cumsille PE. Planned missing data designs in psychologicla research. Psychol Methods. 2006; 11(4):323. https://doi.org/10.1037/1082-989X. 11.4.323. [PubMed: 17154750]

25. Regan AK, Promoff G, Dube SR, Arrazola R. Electronic nicotine delivery systems: adult use and awareness of the "e-cigarette" in the USA. Tob Control. 2013; 22(1):19-23. https://doi.org/ 10.1136/tobaccocontrol-2011-050044. [PubMed: 22034071]

26. Demirtas H, Freels SA, Yucel RM. Plausibility of multivariate normality assumption when multiply imputing non-Gaussian continuous outcomes: a simulation assessment. J Stat Comput Simul. 2008; 78(1):69-84. https://doi.org/10.1080/10629360600903866.

27. Lee KJ, Carlin JB. Multiple imputation for missing data: fully conditional specification versus multivariate normal imputation. Am J Epidemiol. 2010; 171(5):624-632. https://doi.org/ 10.1093/aje/kwp425. [PubMed: 20106935]

28. Fallin A, Goodin A, Lee YO, Bennett K. Smoking characteristics among lesbian, gay, and bisexual adults. Prev Med. 2015; 74:123-130. https://doi.org/10.1016/j.ypmed.2014.11.026. [PubMed: 25485860]

29. Gruskin EP, Greenwood GL, Matevia M, Pollack LM, Bye LL. Disparities in smoking between the lesbian, gay, and bisexual population and the general population in California. Am J Public Health. 2007; 97(8):1496-1502. https://doi.org/10.2105/AJPH.2006.090258. [PubMed: 17600265]

30. CDC. [Accessed May 27, 2016] Current cigarette smoking among adults in the United States. www.cdc.gov/tobacco/data_statistics/fact_sheets/adult_data/cig_smoking/. Published 2016

31. Youatt EJ, Johns MM, Pingel ES, Soler JH, Bauermeister JA. Exploring young adult sexual minority women's perspectives on LGBTQ smoking. J LGBT Youth. 2015; 12(3):323-342. https://doi.org/10.1080/19361653.2015.1022242. [PubMed: 26508993]

32. Wilson H, Bryant J, Ellard J, Howard J, Treloar C. Sexual identity and its relationship to injecting in a sample of disadvantaged young drug users. Drug Alcohol Rev. 2016; 35(2):218-222. https:// doi.org/10.1111/dar.12281. [PubMed: 26084724]

33. Kerr D, Ding K, Burke A, Ott-Walter K. An alcohol, tobacco, and other drug use comparison of lesbian, bisexual, and heterosexual undergraduate women. Subst Use Misuse. 2015; 50(3):340349. https://doi.org/10.3109/10826084.2014.980954. [PubMed: 25488100] 
34. Leibel K, Lee JGL, Goldstein AO, Ranney LM. Barring intervention? Lesbian and gay bars as an underutilized venue for tobacco interventions. Nicotine Tob Res. 2011; 13(7):507-511. https:// doi.org/10.1093/ntr/ntr065. [PubMed: 21498874]

35. Fallin A, Davis B. LGBT organisation successfully advocated for ban on tobacco promotions in San Jose, California. Tob Control. 2016; 25(5):504-505. https://doi.org/10.1136/ tobaccocontrol-2015-052660. [PubMed: 26758029]

36. Al-Delaimy WK, Myers MG, Leas EC, Strong DR, Hofstetter CR. E-cigarette use in the past and quitting behavior in the future: a population-based study. Am J Public Health. 2015; 105(6):12131219. https://doi.org/10.2105/AJPH.2014.302482. [PubMed: 25880947]

37. Grana RA, Popova L, Ling PM. A longitudinal analysis of electronic cigarette use and smoking cessation. JAMA Intern Med. 2014; 174(5):812-813. https://doi.org/10.1001/jamainternmed. 2014.187. [PubMed: 24664434]

38. McRobbie, H., Bullen, C., Hartmann-Boyce, J., Hajek, P. Electronic cigarettes for smoking cessation and reduction; Cochrane Database Syst Rev. 2014. p. CD010216https://doi.org/ 10.1002/14651858.cd010216.pub2

39. Berger, I., Mooney-Somers, J. Smoking cessation programs for lesbian, gay, bisexual, transgender, and intersex people: a content-based systematic review. Nicotine Tob Res. In press. Online September 26, 2016. https://doi.org/10.1093/ntr/ntw216

40. Lee JG, Matthews AK, McCullen CA, Melvin CL. Promotion of tobacco use cessation for lesbian, gay, bisexual, and transgender people: a systematic review. Am J Prev Med. 2014; 47(6):823-831. https://doi.org/10.1016/j.amepre.2014.07.051. [PubMed: 25455123]

41. Grana RA, Ling PM, Benowitz N, Glantz S. Electronic cigarettes. Circulation. 2014; 129(19):e490-e492. https://doi.org/10.1161/CIR-CULATIONAHA.114.008545. [PubMed: 24821830] 


\section{Table 1}

Demographics and Tobacco-Related Variables for Female Participants (2012-2014)

\begin{tabular}{|c|c|c|c|}
\hline Variables & Total sample $(\mathbf{N}=3,906)$ & LGB $(n=572,14.7 \%)$ & Heterosexual/straight $(n=3,327,85.3 \%)$ \\
\hline \multicolumn{4}{|l|}{ Demographics } \\
\hline Age, M, SD & $23.62,1.8$ & $23.66,1.9$ & $23.61,1.8$ \\
\hline \multicolumn{4}{|l|}{ Education, \% } \\
\hline In college & 45.5 & 42.7 & 46.0 \\
\hline College graduate & 39.6 & 30.4 & 41.2 \\
\hline No college & 14.9 & 26.8 & 12.8 \\
\hline \multicolumn{4}{|l|}{ Race/ethnicity, \% } \\
\hline NH white & 50.5 & 36.1 & 52.9 \\
\hline NH African American & 4.7 & 6.9 & 4.3 \\
\hline Hispanic & 13.4 & 16.3 & 12.9 \\
\hline $\mathrm{NH}$ other & 31.4 & 40.7 & 29.9 \\
\hline \multicolumn{4}{|c|}{ Tobacco-related variables (dichotomous), $\%$} \\
\hline Black and mild/cigarillos & 6.6 & 15.5 & 5.1 \\
\hline Electronic cigarettes & 13.0 & 20.9 & 11.6 \\
\hline Hookah & 17.4 & 26.7 & 15.9 \\
\hline Chew & 2.7 & 5.4 & 2.2 \\
\hline Snus & 2.1 & 4.4 & 1.6 \\
\hline Cigarettes & 36.0 & 54.4 & 32.8 \\
\hline Dual or multiple product use & 14.1 & 27.3 & 12.0 \\
\hline Binge alcohol & 70.5 & 72.9 & 70.1 \\
\hline
\end{tabular}

Note: Boldface indicates statistical significance $(p<0.05)$.

LGB, lesbian, gay, and bisexual; NH, non-Hispanic. 
Table 2

Demographics and Tobacco-Related Variables for Male Participants (2012-2014)

\begin{tabular}{|c|c|c|c|}
\hline Variables & Total sample $(\mathrm{N}=4,104)$ & LGB $(n=486,11.9 \%)$ & Heterosexual/straight $(n=3,600,88.1 \%)$ \\
\hline \multicolumn{4}{|l|}{ Demographics } \\
\hline Age, M (SD) & $23.88(1.9)$ & $23.82(2.0)$ & $23.89(1.8)$ \\
\hline \multicolumn{4}{|l|}{ Education, \% } \\
\hline In college & 42.8 & 39.6 & 43.2 \\
\hline College graduate & 34.2 & 34.0 & 34.3 \\
\hline No college & 22.0 & 26.4 & 22.5 \\
\hline \multicolumn{4}{|l|}{ Race/ethnicity, \% } \\
\hline NH white & 46.7 & 34.6 & 48.5 \\
\hline NH African American & 7.1 & 7.4 & 7.0 \\
\hline Hispanic & 13.6 & 18.4 & 13.0 \\
\hline $\mathrm{NH}$ other & 32.6 & 39.6 & 31.5 \\
\hline \multicolumn{4}{|c|}{ Tobacco-related variables (dichotomous), \% } \\
\hline Past-30 day smoking & 51.9 & 55.6 & 47.2 \\
\hline Black and mild/cigarillos & 14.1 & 18.1 & 13.4 \\
\hline Electronic cigarettes & 22.2 & 28.5 & 21.2 \\
\hline Hookah & 24.0 & 28.9 & 23.3 \\
\hline Chew & 12.5 & 16.1 & 12.0 \\
\hline Snus & 8.7 & 14.9 & 7.8 \\
\hline Cigarettes & 48.1 & 55.6 & 47.2 \\
\hline Dual or multiple product use & 25.2 & 34.1 & 24.0 \\
\hline Binge alcohol & 78.8 & 79.3 & 75.9 \\
\hline
\end{tabular}

Note: Boldface indicates statistical significance $(p<0.05)$.

LGB, lesbian, gay, and bisexual; NH, non-Hispanic. 


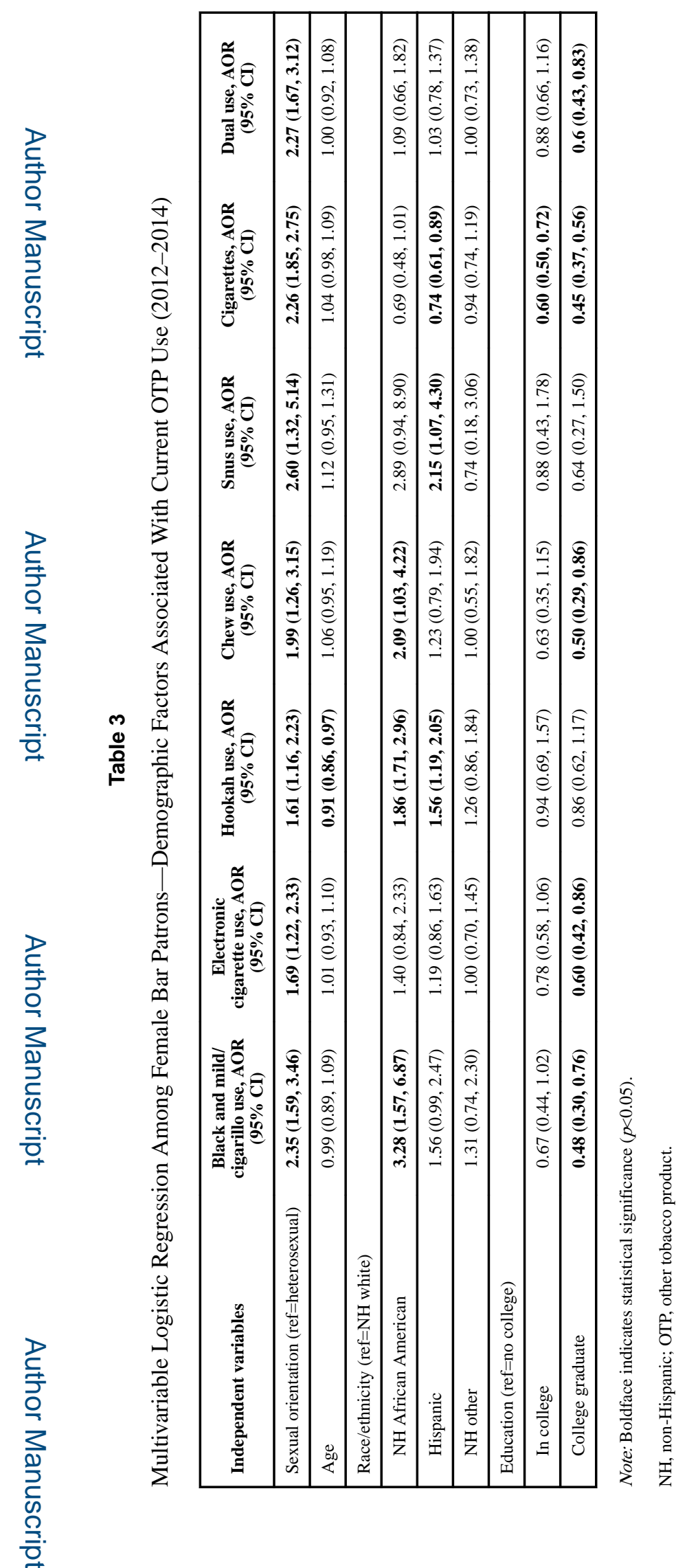

Am J Prev Med. Author manuscript; available in PMC 2018 September 01. 


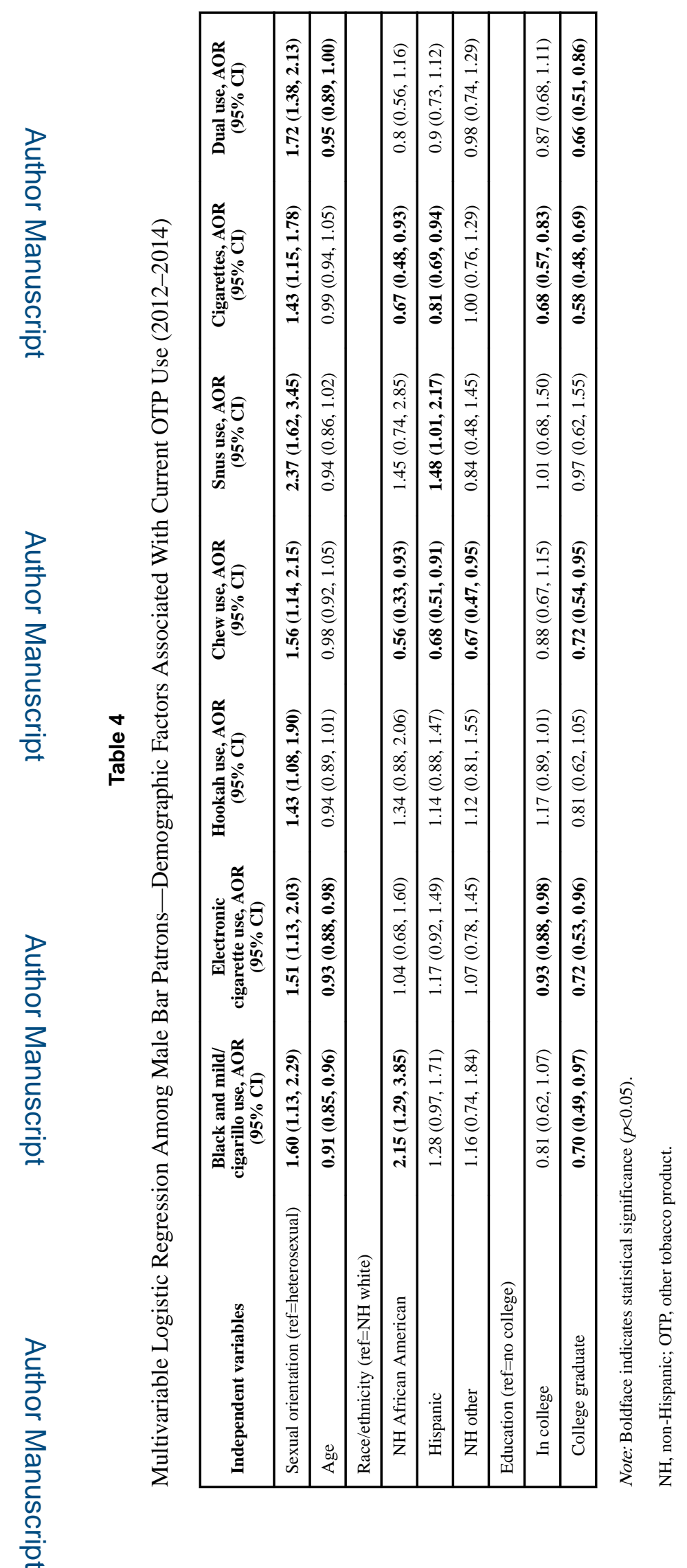

Am J Prev Med. Author manuscript; available in PMC 2018 September 01. 